\title{
VAIKŲ ODONTOLOGINIŲ OPERACIJŲ PREMEDIKACIJOS PRIEMONIŲ PASIRINKIMO IVERTINIMAS
}

\author{
Lina Kalibatienė, Vaiva Skaraitė, Vilma Galdikaitė, Rimvydas Alšauskas, \\ Jonas Lazauskas, Andrius Macas \\ Lietuvos sveikatos mokslu universiteto ligoniné Kauno klinikos
}

Raktažodžiai: vaikų premedikacija, midazolamas, lydejjimas ị operacinę, odontologinès operacijos.

\begin{abstract}
Santrauka
Ikioperaciniam vaikų raminimui taikomi du būdai: tèvų lydejimas ir buvimas kartu su vaiku operacinejje, arba medikamentinès premedikacijos priemonès. Remiantis tyrimais, tèvų lydèjimas į operacinę ir buvimas anestezijos pradžioje nepakankamai mažina procedūros sukeltus neigiamus simptomus, tačiau tèvai yra labiau patenkinti, lydẻdami vaikus ị operacinę. Tyrimo tikslas - nustatyti, kuri ikioperacinè vaikų raminimo priemonè pasirenkama dažniausiai, kokie pasirinkimą lemiantys veiksniai ir koks pasitenkinimas pasirinktaja priemone.

Metodika. Prospektyvinis randomizuotas tyrimas atliktas Lietuvos sveikatos mokslų universiteto ligoninëje Kauno klinikos (LSMUL KK) Veido ir žandikaulių chirurgijos klinikoje 2017 metų kovo - lapkričio ménesiais. Tyrimo metu apklaustas 91 tiriamasis: tẻvai arba artimieji, lydèję vaikus ị planinę odontologinę operaciją, taikant bendrinę nejautrą. Tiriamiesiems buvo pateikta anketa, kurioje reikejjo nurodyti bei įvertinti pasirinktą premedikacijos priemonę, jos veiksmingumą ir pasitenkinimą. Duomenų analizè atlikta IBM SPSS 22.0 programa. Skirtumai tarp grupiu laikyti statistiškai reikšmingais, kai $\mathrm{p}<0,05$.

Rezultatai. Dažniausiai $(64,8 \%)$ pasirinkta vaikų premedikacijos priemoné buvo ejjimas kartu ị operacinę ir buvimas anestezijos pradžioje. Didele dalis apklaustujjų ịvardijo „labai svarbias“ tokio pasirinkimo priežastis: galimo šalutinio vaistų poveikio išvengimas (73\%), kuo veiksmingesnis neigiamų ikioperacinių reiškinių slopinimas (59\%), kuo priimtinesnis $(63 \%)$ ir patogesnis $(59 \%)$ vartojimo būdas. Premedikacija midazolamu (tabletės arba tirpalas) yra veiksmingesne, t.y. pasižymi geresniu poveikiu elgsenai, bendrajai ir emocinei būklei prieš operaciją, negu
\end{abstract}

vaiko lydejimas ị operacinę ir buvimas anestezijos pradžioje. Pasitenkinimas premedikacijos priemoniu (midazolamo tabletès, tirpalas ir paciento lydejjimas ì operacinę) pasirinkimu statistiškai reikšmingai nesiskyrè.

Išvada. Daugelis respondentų rinkosi vaikų lydejjimą i operacinę. Tẻvų nuomone, midazolamo vartojimas buvo veiksmingesnis, nors pasitenkinimo skirtumo tarp farmakologinès (midazolamas) ir nefarmakologinės premedikacijos nestebèta.

\section{İvadas}

Didelis odontologinėmis ligomis sergančių vaikų skaičius išryškina vis didejjančią dantų priežiūros svarbą. Nemalonūs, skausmingi ir bauginantys potyriai, susiję su vaikų dantų ligomis ir jų gydymu, gali sukelti psichologinių problemų [1-3], todèl ikioperacinè sedacija tampa labai svarbi [4]. Siekiant sumažinti neigiamą psichologinị poveikị vaikui, anesteziologai prieš odontologines operacijas arba tam tikras medikamentines premedikacijos priemones siūlo rinktis tèvų lydejjimą ir buvimą kartu su vaiku operacinejje [5]. Kelių tyrimų duomenys parodè, kad prieš odontologines procedūras vaikų premedikacijai gali būti vartojamas midazolamas. Tyrimai atskleide, kad midazolamas gerina pooperacinę elgseną ir nuotaiką, mažina po procedūrų bei operacijų galinčius atsirasti miego, valgymo sutrikimus bei kitus nepageidaujamus reiškinius [6-8]. Šis preparatas yra dažno pasirinkimo prieš vaikų odontologines operacijas, kadangi saugus, greitai ir trumpai veikiantis, sukeliantis retrogradinę amneziją [9]. Remiantis tyrimais, tėvų lydejjimas i operacinę ir buvimas šalia anestezijos pradžioje nepakankamai mažina procedūros sukeltus neigiamus simptomus, tačiau tėvai tokia premedikacija yra labiau patenkinti [10]. Šiuo metu trūksta tyrimų, kuriuose būtų vertinama, kodèl ir kokias ikioperacines raminimo priemones renkasi tèvai prieš vaikų odontologines operacijas, bei koks pasitenkinimas pasirinkta priemone.

Tyrimo tikslas: nustatyti ikioperacinę vaikų raminimo 
priemonę, kurią dažniausiai renkasi tėvai ar vaikus į odontologines operacijas lydintys artimieji; išsiaiškinti svarbiausius veiksnius, lemiančius ikioperacinès raminimo priemonès pasirinkimą; ịvertinti pasitenkinimą pasirinkta priemone.

\section{Tyrimo objektas ir metodai}

Prospektyvinis randomizuotas tyrimas atliktas LSMUL KK Veido ir žandikaulių chirurgijos klinikoje 2017 metų kovo - lapkričio mėnesiais. Tyrimo metu buvo apklausti tèvai arba artimieji, lydèję vaikus ị planinę odontologinę operaciją, taikant bendrinę nejautrą. Iš viso tyrime dalyvavo 91 tiriamasis. Visi, supažindinti su tyrimo tikslu ir eiga, pasirašè informuoto asmens sutikimą dalyvauti tyrime. Leista pasirinkti vieną iš premedikacijos būdų: midazolamo skyrimą tabletėmis, midazolamo skyrimą tirpalo forma po liežuviu, tiopentalio skyrimą i tiesiają žarną (klizma) arba vaiko lydejimą ị operacinę ir buvimą anestezijos indukcijos metu. Tiriamiesiems buvo pateikta anketa, kurioje reikejjo nurodyti pasirinktą premedikacijos būdą, pasirinkimą lèmusių veiksnių svarbumą (labai svarbu; svarbu; nelabai svarbu; nesvarbu) ir ịvertinti pasirinktos priemonès veiksmingumą bei pasitenkinimą pasirinkimu. Mūsų tyrime premedikacijai rekomenduojama saugi ir veiksminga tablečių formos midozalamo dozè buvo $0,2-0,6 \mathrm{mg} / \mathrm{kg}$ (L. Kalibatienè, 2015) [11]. Tyrime buvo naudojamas peroralinis tirpalas po liežuviu, paruoštas iš intraveninio midazolamo, kurio pasirinkta dozė $0,2 \mathrm{mg} / \mathrm{kg}$. Mūsų atliktame tyrime nè vienu atveju vaikui paskirta dozè nesukèlè perdozavimo reiškinių, t.y. nebuvo kliniškai reikšmingo kvẻpavimo ar kardiovaskulinès sistemos slopinimo. Tyrimui atlikti gautas LSMU Bioetikos centro leidimas (2017-02-24, Nr. BEC-MF-307). Duomenų analizè atlikta IBM SPSS 22.0 programa. Kiekybinei kintamujų analizei naudotas vidurkis ir standartinis nuokrypis, o kokybiniam palyginimui tarp grupių naudota $\mathrm{Chi}$ - kvadrato testas, Kruskalio Voliso (Kruskal-Wallis) testas. Skirtumai tarp grupių laikyti statistiškai reikšmingais, kai p<0,05.

\section{Rezultatai}

Tyrime dalyvavo 91 tiriamasis. Iš jų 78\% sudarè mamos, $21 \%$ - téčiai ir 1\% - močiutès. Vidutinis tiriamujų

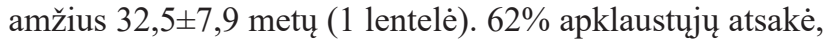
kad anksčiau vaikui nebuvo atlikta operacija, kurios metu būtų taikyta anestezija.

Dažniausiai $(64,8 \%)$ pasirinkta ikioperacinè vaiko ra-

1 lentelè. Tiriamujų (tėvų ar lydinčių artimųjų) amžiaus pasiskirstymas pagal raminimo priemonių grupes.

\begin{tabular}{|c|c|c|c|c|}
\hline & $\begin{array}{c}\text { Lydėjimas i } \\
\text { operacinę }\end{array}$ & $\begin{array}{c}\text { Midazolamo } \\
\text { tabletė }\end{array}$ & $\begin{array}{c}\text { Midazolamo } \\
\text { skysta forma }\end{array}$ & $\mathbf{P}$ \\
\hline Amžius & $31,7 \pm 5,8$ & $34,4 \pm 9,8$ & $33,7 \pm 8,1$ & 0,668 \\
\hline
\end{tabular}

minimo priemonè buvo ejimas kartu ị operacinę ir buvimas šalia vaiko anestezijos pradžioje. Midazolamą tabletemis pasirinko $19,8 \%$, o tirpalo forma po liežuviu - $15,4 \%$ apklaustuju (1 pav.). Tiopentalis ị tiesiają žarną šiame tyrime nebuvo pasirinktas.

Rinkdamiesi ikioperacinę raminimo priemonę, daugelis apklaustujų ịvardijo šias „labai svarbias“ pasirinkimo priežastis: galimo vaistų šalutinio poveikio išvengimas (73\%), kuo veiksmingesnis neigiamų ikioperacinių reiškinių slopinimas $(59 \%)$, priimtinesnis $(63 \%)$ ir patogesnis $(59 \%)$ vartojimo būdas.

Vertindami pasirinktosios priemonès veiksmingumą, tiriamieji aukščiausiu balu „labai gerai“ ìvertino midazolamo, skirto tirpalo forma po liežuviu, poveikį elgsenai $(50 \%)$, bendrajai $(50 \%)$ ir emocinei $(57,1 \%)$ būklei prieš operaciją. Midazolamo tabletès skyrimas , labai gerai“ ịvertintas vaiko elgsenai $(44,4 \%)$, bendrajai $(44,4 \%)$ ir emocinei $(44,4 \%)$ būklei prieš operaciją. Tarp šių midazolamo skyrimo būdų statistiškai reikšmingo skirtumo nebuvo $(p>0,05)$. Priešingai, respondentai, pasirinkę èjimą su vaiku ị operacinę ir buvimą anestezijos indukcijos metu, rečiausiai aukščiausiu balu ,labai gerai“ ịvertino pasirinktos ikioperacinès raminimo priemonès veiksmingumą. Vaiko lydèjimo ị operacinę ir buvimo anestezijos pradžioje poveikis elgsenai, bendrajai ir emocinei būklei prieš operaciją, ,labai gerai“ įvertintas tik $22 \%, 20,3 \%$, ir $22 \%$ atvejų (2 pav.). Šis skirtumas tarp skirtingas ikioperacines raminimo priemones (midazolamo tablečių bei geriamojo tirpalo ar paciento lydejjimo ị operacinę) pasirinkusiųjų respondentų yra statistiškai reikšmingas $(\mathrm{p}<0,05)$.

Pasitenkinimas ikioperacine sedacija buvo ịvertintas „labai gerai“ $24,2 \%$, „gerai“ $50,5 \%$, ,blogai“ $1,1 \%$, „labai blogai“ $0 \%$, ,nežinojo“ $24,2 \%$ respondentų. $52,7 \%$ respondentų teigè, kad vèl rinktųsi tą pati premedikacijos būdą, 6,6\% nebesirinktų, o 40,7\% nepateikè atsakymo. Labiausiai ikioperacine sedacija patenkinti buvo apklaustieji, pasirinkę midazolamo tirpalą po liežuviu (42,9\%), o mažiausiai - pasirinkusieji vaiko lydejjimą ị operacinę (18,6\%). Šis skirtu-

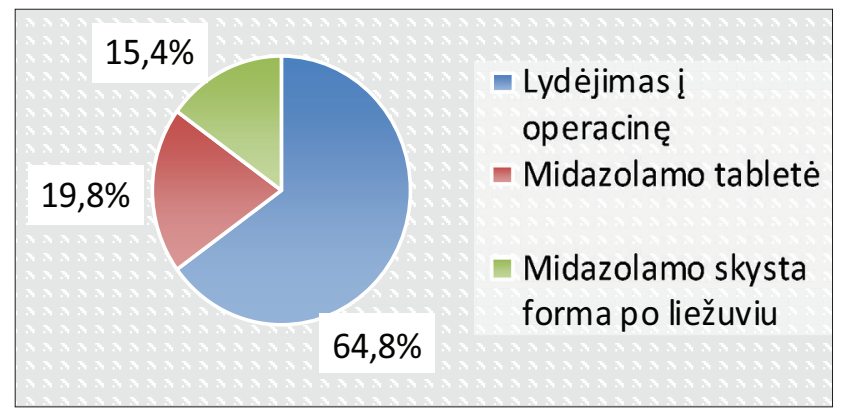

1 pav. Premedikacijos priemonių pasirinkimas (proc.) 
mas nėra statistiškai reikšmingas. Daugiausiai teigusių, kad kitą kartą rinktųsi tokią pat ikioperacinę vaiko raminimo priemonę, buvo pasirinkusieji midazolamo tirpalą $(78,6 \%)$, midazolamo tabletę $(77,8 \%)$, o mažiausiai - pasirinkusieji vaiko lydejjimą ị operacinę (39\%) (3 pav.). Lyginant ikioperacinių priemonių pasirinkimą kitą kartą (midazolamą tabletėmis, midazolamo tirpalą ar paciento lydejjimą ị operacinę), gautas statistiškai reikšmingas skirtumas $p<0,05$. Daugiausia nenorinčiujų, kad dar kartą būtų skiriama tokia pati ikioperacinè sedacija, buvo grupeje, pasirinkusioje vaiko lydejjimą ị operacinę $(8,5 \%)$.

\section{Rezultatų aptarimas}

Daugiausia (73\%) apklaustujų, rinkdamiesi ikioperacinę raminimo priemonę, sieke išvengti galimo šalutinio vaistų poveikio. Skiriant vaistus per burną, gali būti sudètinga titruoti sedacijos gyli [1], o $1 \mathrm{mg} / \mathrm{kg}$ midazolamo dozé gali sukelti kvépavimo sistemos slopinimą, tačiau mažesnè dozé $(0,75 \mathrm{mg} / \mathrm{kg})$ šio nepageidaujamo poveikio nesukelia [12]. Iki šiol vis dar nenustatyta, koks yra ilgalaikis anestetinių medžiagų, tarp jų ir midazolamo, poveikis vaiko neurologinei būklei: mokymosi galimybėms, elgsenai, todèl atliktų tyrimų rezultatai kontroversiški [4]. Galimai dèl vaisto šalutinių reiškinių baimès, dauguma $(64,8 \%)$ tiriamujų pasirinko vaiko lydèjimą i operacinę ir buvimą anestezijos indukcijos metu. Renkantis šị raminimo metodą, svarbu suprasti, kad tèvų nerimas ar kritika operacinèje gali padidinti vaiko nerimą, sukelti papildomą stresą medicinos personalui ir pailginti indukciją [13].

Rinkdamiesi ikioperacinę raminimo priemonę, respondentai aukščiausiai vertino kuo priimtinesni (63\%) ir kuo patogesnị (59\%) vartojimo būdą. Mūsų tyrime visais atvejais, prieš operaciją pasirinkus medikamentinę raminimo prie-

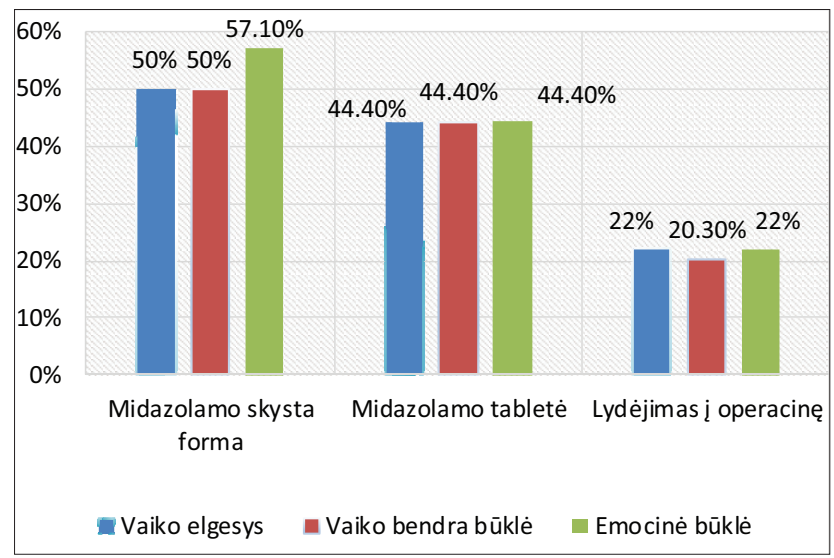

2 pav. Skirtingų premedikacijos priemonių veiksmingumas vaiko elgesio, bendrosios ir emocinès būklès atžvilgiu (proc.). monę, buvo skiriamas midazolamas, kuris pasaulyje laikomas vaikų premedikacijos ,aukso standartu“ [10]. Galimai dèl patogesnio midazolamo vartojimo galimybių nè vienu atveju nepasirinktas tiopentalio skyrimas ị tiesiają žarną.

Kaip labai svarbų kriterijų, renkantis ikioperacinę raminimo priemonę, $59 \%$ respondentų nurode kuo veiksmingesni neigiamų ikioperacinių reiškinių slopinimą. Ikioperaciniu laikotarpiu patiriamas nerimas sukelia hormoninius, metabolinius ir imuninius pokyčius, kurie aktyvina pagumburio- hipofizès-antinksčių ašį, didina gliukokortikoidų ir adrenalino išsiskyrimą i kraują. Vaiko nerimas sukelia fiziologinius pokyčius, tokius kaip širdies susitraukimų dažnio ir kraujospūdžio didejjimas [5] ir susijęs su didesne pooperacinių infekcijų rizika [13]. Nustatyta, kad ikioperacinis nerimas susijęs su didesniu skausmu pooperaciniu laikotarpiu [12] ir gali lemti vaiko psichologinius sutrikimus, tokius, kaip per didelis nerimas, atsiskiriant nuo tėvų, šlapimo nelaikymas, valgymo ir miego sutrikimai $[14,13]$, todèl tèvams labai svarbu pasirinkti tinkamą vaiko raminimo priemonę.

Tyrimo rezultatai parode statistiškai reikšmingą geresni midazolamo poveikị vaiko bendrajai, emocinei būklei ir elgsenai, nors pasitenkinimo ikioperacine raminimo priemone atžvilgiu, skirtumo tarp pasirinkusiųų midazolamą ir vaiko lydejimą ị operacinę, nenustatyta. Nepaisant to, dauguma apklaustujų, pasirinkusių premedikaciją midazolamu, nurodè, kad kitą kartą rinktųsi tokią pat ikioperacinę priemonę. Sadeghi su bendraautoriais nustate, kad vaiko premedikacija peroraliniu midazolamu, kartu su tèvų lydèjimu ị operacinę, ženkliai padidina tėvų pasitenkinimą perioperaciniu periodu, lyginant su kontroline grupe, kurioje buvo skiriama tik peroralinio midazolamo [14]. Remiantis Kain su bendraautoriais atlikto tyrimo rezultatais, vaikų, gavusių premedikaciją midazolamu, lydèjimas į operacinę ir buvimas iki indukcijos pradžios, nesumažino vaikų nerimo, lyginant su grupe, kurioje buvo skiriama tik premedikacija midazolamu, nors tèvai, lydèję vaikus ị operacinę, buvo labiau patenkinti [15]. Kain ir Sadeghi tyrimai parodé, kad tèvų èjimas ị operacinę su vaiku, kuriam paskirta premedikacija midazolamu, didina

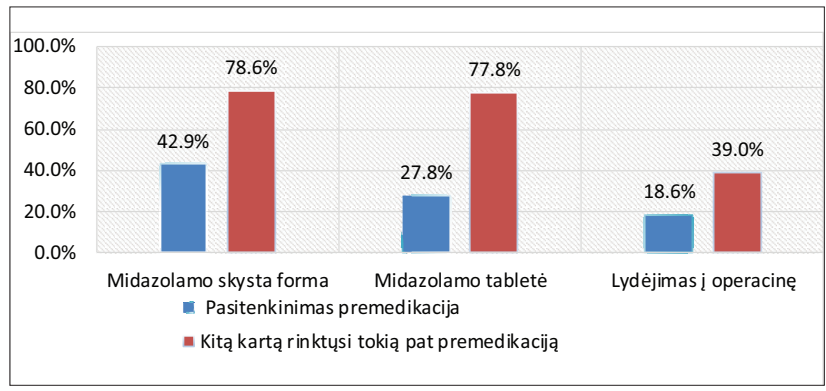

3 pav. Pasitenkinimas premedikacijos priemonių pasirinkimu (proc.). 
tėvų pasitenkinimą, tačiau, kaip nustatėme, vien tik vaiku lydẻjimas ị operacinę tèvų pasitenkinimo nedidina. Lyginant Kain ir mūsų tyrimo rezultatus, galima įžvelgti, kad midazolamas turi didelị poveikị vaiko ikioperaciniam raminimui. Pagal Sadeghi ir Palermo, ši kombinacija ryškiai pagerina pediatrinių pacientų elgseną ir bendrają būklę $[14,16]$, todèl, siekiant geresnio vaikų raminimo ir tėvų pasitenkinimo, būtų tikslinga apsvarstyti šių dviejų ikioperacinių raminimo priemonių kombinaciją.

\section{Išvados}

1. Vaiko lydejjimas ị operacinę ir buvimas anestezijos indukcijos metu yra dažniausiai pasirenkama ikioperacinè raminimo priemonè.

2. Renkantis ikioperacinę raminimo priemonę, respondentų manymu, svarbiausia išvengti galimo šalutinio vaistų poveikio. Mažiau svarbus yra kuo veiksmingesnis neigiamų ikioperacinių reiškinių slopinimas, bei kuo priimtinesnis ir patogesnis vartojimo būdas.

3. Nors pasitenkinimas pasirinkta priemone statistiškai reikšmingai tarp grupių nesiskyre, pasirinkusieji premedikaciją midazolamu (tablečių ar tirpalo forma) geriausiai ivvertino pasirinktosios priemonès poveikị vaiko bendrajai būklei, elgsenai bei emocinès įtampos mažinimui ir išreiškè didžiausią norą kitą kartą rinktis tokią pat premedikacijos priemonę.

\section{Literatūra}

1. Sheiham A. Dental caries affects body weight, growt hand quality of life in preschool. Br Dent J. 2006;201(10):625-626.

https://doi.org/10.1038/sj.bdj.4814259

2. Berg J, Slayton RA. Early Childhood Oral Health. 1st ed. Hoboken, NJ, USA: Wiley-Blackwell. 2009.3. Edelstein B, Vargas C, Candelaria D, Vemuri M. Experience and policy implications of children presenting with dental emergencies to US pediatric dentistry training programs. Pediatr Dent. 2006;28:431-437.4. Nelson TM, Xu Z. Pediatric dental sedation: challenges and opportunities. Clin Cosmet Investig Dent. 2015; 7:97-106.

https://doi.org/10.2147/CCIDE.S64250

5. Abdallah C, Hannallah R. Premedication of the child undergoing surgery. Middle East J Anaesth. 2011; 21(2):165-74.

6. Ghali AM, Mahfouz AK, Al-Bahrani M. Preanesthetic medication in children: a comparison of intranasal dexmedetomidine versus oral midazolam. Saudi J Anaesth. 2011;5(4):387-91.

https://doi.org/10.4103/1658-354X.87268

7. Rosenbaum A, Kain ZN, Larsson P, Lönnqvist PA, WolfAR. The place of premedication in pediatric practice. Paediatr Anaesth. 2009;19:817-28.

https://doi.org/10.1111/j.1460-9592.2009.03114.x

8. Kain ZN, Mayes LC, Wang SM, Hofstadter MB. Postoperative behavioral outcomes in children: effects of sedative premedication. Anesth. 1999;90:75865.

https://doi.org/10.1097/00000542-199903000-00018

9. Gazal G, Fareed WM, Zafar MS , Al-Samadani KH. Pain and anxiety management for pediatric dental procedures using various combinations of sedative drugs: A review. Saudi Pharm J. 2016;24(4):379-85.

https://doi.org/10.1016/j.jsps.2014.04.004

10. O'Sullivan M, Wong G.K. Preinduction techniques to relieve anxiety in children undergoing general anaesthesia. Contin Educ Anaesth Crit Care Pain. 2013;13(6):196-199.

https://doi.org/10.1093/bjaceaccp/mkt014

11. Kalibatienè L. Geriamojo midazolamo sedacinio poveikio ịvertinimas vaikams prieš odontologines operacijas [Daktaro disertacija] 2015.

12. Kaviani N, Shahtusi M, Haj Norousali Tehrani M, Nazari S. Effect of oral midazolam premedication on children's co-operation before general anesthesia in pediatric dentistry. J Dent (Shiraz). 2014;15(3):123-128.

13. McCann ME, Kain ZN. The management of preoperative anxiety in children: an update. Anesth Analg. 2001;93(1):98-105. https://doi.org/10.1097/00000539-200107000-00022

14. Sadeghi A, Khaleghnejad Tabari A, Mahdavi A, Salarian S, Razavi SS. Impact of parental presence during induction of anesthesia on anxiety level among pediatric patients and their parents: a randomized clinical trial. Neuropsychiatr DisTreat. 2017;20(12):3237-3241.

https://doi.org/10.2147/NDT.S119208

15. Kain ZN, Mayes LC, Wang SM, Caramico LA, Krivutza DM, Hofstadter MB. Parental presence and a sedative premedication for children undergoing surgery: a hierarchical study. Anesth. 2000;92(4):939-46.

https://doi.org/10.1097/00000542-200004000-00010

16. Palermo TM, Tripi PA, Burgess E. Parental presence during anaesthesia induction for outpatient surgery of the infant. Paediatr Anaesth. 2000;10(5):487-491.

https://doi.org/10.1046/j.1460-9592.2000.00552.x

\section{EVALUATION OF PARENTS' REASONS FOR CHOOSING AN APPROPRIATE PREMEDICATION METHOD BEFORE PEDIATRIC DENTAL SURGERY PROCEDURES AND FULFILLMENT OF THE PREMEDICATION}

\section{Kalibatienė, V. Skaraitė, V. Galdikaitė, R. Alšauskas,}

\section{J. Lazauskas, A. Macas}

Keywords: sedative premedication, midazolam, parental presence at induction of anaesthesia (PPIA), dental surgery.

Summary

Introduction. Where is a growing importance of sedation before pediatric dental surgery procedures which allows to provide procedure in a minimally traumatic way and prevent unpleasant experiences which can cause psychologic harm. In purpose to reduce ne- 
gative psychological effects, anesthesiologists use either parental presence at induction of anaesthesia (PPIA)or sedative premedication. According to research, PPIA usually does not reduce negative symptoms sufficiently, although parental satisfaction is enhanced when they accompany their children at induction of anaesthesia.

The aim of the study. To assess most preferred preoperative calming (medication either PPIA) measure, the reasons for choosing and the fulfillment of the preoperative calming measure.

Materials and methods. A prospective study wasaccomplished in the Department of Maxillofacial Surgery at Lithuanian University of Health Sciences Hospital from 2017 March to 2017 November. Parents of 91 children undergoing dental surgery were randomly selected and interviewed using questionnaire which contained questions about which type of the premedication did they choose, how do they evaluate effectiveness and satisfaction of the premedication. IBM SPSS 22.0 program was used to analyze data statistically. Differences were considered as statistically significant when $\mathrm{p}<0.05$.

Results. Most common approach $(64, \%)$ for dealing with presurgical anxiety was accompanying to the operating room and staying by the patient while administering anesthesia. When choosing a calming measure $73 \%$ of participants signed the highest priority to the prevention of possible side effects of a remedy, $63 \%$ to the route of administration acceptability, $59 \%$ to the efficiency of managing presurgical negative effects and the satisfactory aspect of the procedure. The midazolam (liquid/tablet form) has greater effect on the overall well-being, on the child's behavior and on the emotional well-being compared to PPIA group. However, no significant difference of the satisfaction was observerd between midazolam and PPIA groups.

Conclusion. Majority of respondents chose to accompany a child to a surgery and be present during anesthesia. Although midazolam weighed effects of premedication on a child's overall well-being, behavior and emotional state prior to a surgery most positively, satisfaction of the preoperative calming measure wasn'tdifferent between pharmacological (midazolam) and non-pharmacological premedication.

Correspondence to: jonaslazauskas@yahoo.com

Gauta 2019-09-09 